The Bangladesh Veterinarian (2011) 28(1) : 8 - 18

\title{
Prevalence of Salmonella infection in naturally infected layer birds in Bangladesh
}

\author{
M. R. Rahman, A. B. M. Shahinuzzaman, A. K. Saha, M. A. Sufian, M. H. Rahman \\ and M. M. Hossain* \\ Department of Pathology, Faculty of Veterinary Science, Bangladesh Agricultural \\ University, Mymensingh-2202, Bangladesh
}

\begin{abstract}
The seroprevalence, cultural prevalence and pathological study of Salmonella infections in chickens of selected layer farms of Birgonj Upazila (Sub-district), Dinajpur were determined. A total of 175 blood samples were tested randomly by locally prepared Salmonella coloured antigen for seroprevalence study. Out of 96 cloacal swabs, 80 samples from live birds ( 36 from seropositive and 44 from seronegative) and 16 samples from dead birds were collected to determine the cultural prevalence of Salmonella organisms. Postmortem examination was done in 16 dead birds. Using whole blood agglutination test (WBA) with locally prepared Salmonella Pullorum coloured antigen, the overall seropositive prevalence was $46.2 \%$. The seroprevalence decreased with age of birds. The cultural prevalence in seropositive was $33.3 \%$ and in seronegative $22.7 \%$. In dead birds, the cultural prevalence using cloacal swab was $25 \%$. A total 26 Salmonella were isolated, 27\% Salmonella Pullorum, 58\% Salmonella Gallinarum and 15\% paratyphoid group of Salmonella. Isolation rate of Salmonella from cloacal swabs was significantly higher in seropositive than seronegative group. Grossly, the livers were friable, with bronze discolouration and necrotic foci, there was severe congestion in the lung, congested haemorrhagic egg follicles with stalk formation and enlarged discoloured spleen. Microscopically, there was focal necrosis and degeneration with leukocytic infiltration in liver, congestion and pneumonic lesions in the lung and various degrees of catarrhal to haemorrhagic enteritis in the intestine. In the egg follicles, congestion and haemorrhage with leukocytic infiltration and enlarged spleen with white necrotic foci were detected. In future, isolated Salmonella organisms may be used for vaccine production, serotyping and antibiotic sensitivity test. (Bangl. vet. 2011. Vol. 28, No. 1, 8 - 18)
\end{abstract}

\section{Introduction}

Salmonella infections are major problems for poultry industry in Bangladesh, and have public health importance (Islam et al., 2007; Haider et al., 2008). Salmonella Pullorum causes the disease pullorum, which is transmitted vertically from parent to offspring. Fowl typhoid, caused by Salmonella Gallinarum, is an acute or chronic disease that most often affects mature birds, and is a serious problem resulting in mortality and lowered egg production and hatchability (Christensen et al., 1996; Khan

\footnotetext{
* Corresponding author:- E-mail: mmhossain04@yahoo.com.au
} 
et al., 1998). Salmonella Gallinarum can produce lesions in chicks, indistinguishable from those associated with pullorum disease.

The seroprevalence of Salmonella infection is $45.9 \%$ in layer birds at Mymensingh district (Ahmed et. al., 2008). Village chickens can act as a reservoir of salmonellosis (Bouzoubaa et al., 1992). Transmission is primarily through the egg but also via direct or indirect contact with infected birds. Infection transmitted via egg or hatchery contamination usually results in death up to 2-3 weeks of age (Wigley et al., 2001; World Poultry VIV, 2008). The birds that survive clinical disease when infected at a young age may show few signs of infection but can act as carriers (Berchieri et al., 2001). Environmental factors such as air, dirty litter and unclean facilities, and vectors, such as insects, humans, and rodents are responsible for Salmonella contamination in poultry farms (Jones et al., 1991; Hoover et al., 1997; Amick-Morris, 1998). The prevalence of salmonellosis in breeder flocks and specially layer flocks is increasing in Bangladesh. This study was undertaken (a) to determine the seroprevalence of Salmonella infection using locally prepared Salmonella Pullorum coloured antigen in layer birds at Dinajpur district in Bangladesh, (b) to determine correlation between cultural prevalence and seroprevalence and (c) to study the pathological lesions of organs of Salmonella-infected birds.

\section{Materials and Methods}

\section{Poultry farms}

Eight layer poultry farms (4 grower, age 13-18 weeks; 4 layer, age 22-52 weeks) of Birgonj Upazila under Dinajpur District, Bangladesh were selected.

Seroprevalence study by whole blood agglutination (WBA) test

The study was conducted from November 2009 to April 2010. Blood samples were collected from chickens of 8 layer farms, which contained 30,500 birds and had no history of using Salmonella vaccine. At the rate of $0.8 \%$ (conventional method of seroprevalence determination), 175 birds were tested randomly. Sterile disposable syringe was used for collection of $3 \mathrm{ml}$ blood from wing vein under aseptic condition. Birds were divided into two groups, grower (9-20 weeks) and layer (21-80 weeks). One drop of rapidly collected blood and one drop of Salmonella coloured antigen were taken in glass slide and mixed well with toothpick and rocking. In positive cases granules observed within two minutes and graded +++ highly positive response, ++ moderate, + lower positive response and - without any reaction (Fig. 1; Muktaruzzaman et al., 2010). However, all the reactions were graded together for considering as positive case. 

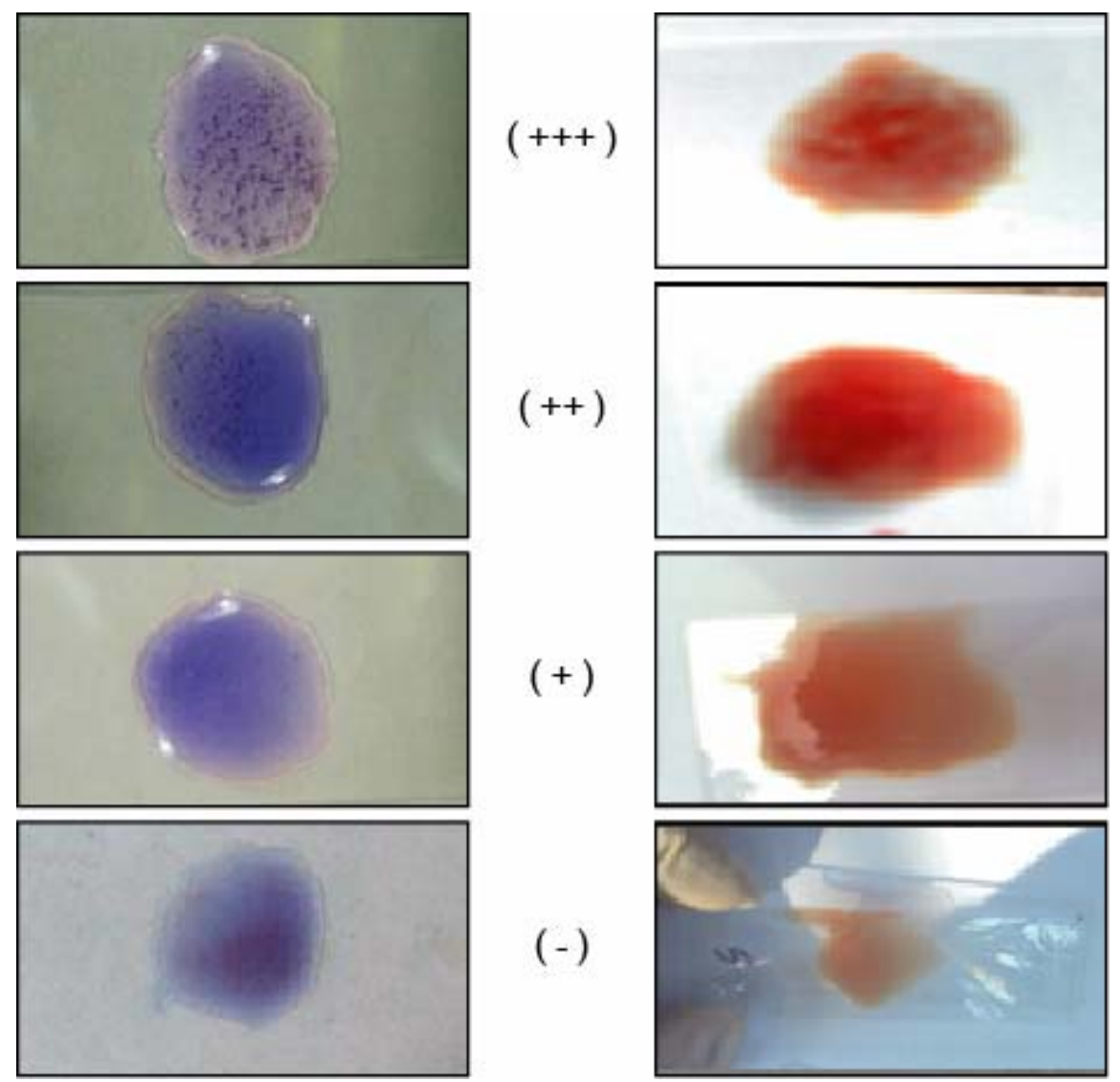

Fig. 1. Whole blood agglutination test (A) Serum, (B) Blood

\section{Isolation and identification of Salmonella organisms}

A total 80 cloacal swabs ( 36 from seropositive; 44 from seronegative birds) were collected from the same flock at the same time as the seroprevalence study. Postmortem examinations of 16 dead birds were performed from 8 poultry farms. All the cloacal swabs were collected in test tubes containing $10 \mathrm{ml}$ tetrathionate broth. Iodineiodide solution $(200 \mu \mathrm{l})$ was added in each test tube just before the swab was mixed in tetrathionate broth. For isolation and identification of Salmonella organisms, the samples were stored in icepack with sunlight-protected black box and carried to the laboratory. Tetrathionate broth (TTB), nutrient broth (NB), Salmonella-Shigella (SS) agar, brilliant green agar (BGA), blood agar (BA), Mac Conkey agar, eosin methylene blue (EMB) agar, triple sugar iron (TSI) agar, nutrient agar (NA), bacteriological peptone, methyl red-Voges Proskauer (MR-VP) medium, Gram's stain and motility test were used for the isolation and characterization of organisms (Merchant and Packer, 1967; OIE Manual, 2004). 
Maintenance of stock culture

To preserve the isolated organisms for further studies, the organisms from pure culture were inoculated into tubes containing nutrient agar slant and incubated at $37^{\circ} \mathrm{C}$ for 24 hours. After the growth of organisms, the tubes were sealed with light liquid paraffin and kept at $4^{\circ} \mathrm{C}$.

Gross pathology

During the seroprevalence study, necropsy of dead birds was done routinely. Gross tissue changes at necropsy were recorded and representative tissue samples were preserved in 10\% neutral buffered formalin for histopathological studies.

\section{Histopathology}

The tissues were trimmed to $1.5 \times 1 \mathrm{~cm}$ size, then kept in running tap water overnight to wash out formalin. Dehydration was done in ascending grades of alcohol, 50, 70, 80, 95\% and three changes of absolute alcohol for one hour in each. Sections were cleaned in two changes of chloroform, one and half an hours for each. Tissues were embedded in two changes of melted paraffin wax at $56^{\circ} \mathrm{C}$, one and half an hours for each. Blocks were sectioned at $5 \mu \mathrm{m}$ thickness. The sections were allowed to spread on warm water bath $\left(45^{\circ} \mathrm{C}\right)$ and taken on grease-free glass slides. A small amount of gelatin was added to the water bath for better adhesion of the section to the slide. The slides were air-dried and kept in cool place, and stained routinely (Luna, 1968).

\section{Photomicrography}

Photomicrography was taken using compound microscope with "Sony" digital camera.

\section{Results and Discussion}

Birds $(n=175)$ were randomly tested for seroprevalence using whole blood agglutination test (WBA) with locally prepared Salmonella Pullorum coloured antigen in the selected eight layer farms. Samples $(n=80)$ of cloacal swabs (36 seropositive; 44 seronegative birds) were taken for culture. These samples were taken from four growers (non-production stage) and four layer (production stage) farms. Post-mortem examination of 16 laying birds was performed from the same layer farms.

Seroprevalence of Salmonella infection by whole blood agglutination (WBA) test

The results of the seroprevalence study by WBA test are shown in Table 1 . The overall seroprevalence was $52.6 \%$ (Table 1 ) in grower birds. In layer chickens the overall seroprevalence was $38.7 \%$ (Table 1) in layers birds. The average overall seroprevalence of both growers and layers was $46.2 \%$ (Table 1 ). 
Table 1. Overall seroprevalence of Salmonella infection in both grower and layer groups of poultry

\begin{tabular}{|c|c|c|c|c|c|c|c|c|c|c|}
\hline \multirow[t]{2}{*}{ Farm No. } & \multirow[t]{2}{*}{$\begin{array}{l}\text { Farm } \\
\text { type }\end{array}$} & \multirow{2}{*}{$\begin{array}{l}\text { Age of } \\
\text { birds } \\
\text { (Week) }\end{array}$} & \multirow{2}{*}{$\begin{array}{c}\text { No. of } \\
\text { tested } \\
\text { blood } \\
\text { samples }\end{array}$} & \multirow{2}{*}{$\begin{array}{c}\text { Average } \\
\text { seronegative }\end{array}$} & \multirow{2}{*}{$\begin{array}{c}\text { Average } \\
\text { seronegative } \\
\text { prevalence }\end{array}$} & \multicolumn{4}{|c|}{$\begin{array}{c}\text { Average } \\
\text { seropositive }\end{array}$} & \multirow{2}{*}{$\begin{array}{c}\text { Average } \\
\text { seropositive } \\
\text { prevalence \% }\end{array}$} \\
\hline & & & & & & +++ & ++ & + & Total & \\
\hline F-1 to F-4 & Grower & $13-18$ & 95 & 45 & 47.3 & 4 & 16 & 30 & 50 & 52.6 \\
\hline F-5 to F-8 & Layer & 22.52 & 80 & 49 & 61.2 & 2 & 12 & 17 & 31 & 38.7 \\
\hline Total & & & 175 & 94 & 53.7 & 6 & 28 & 47 & 81 & 46.2 \\
\hline
\end{tabular}

Isolation and identification of Salmonella organisms

A total of 96 (16 dead; 80 live) cloacal swabs were cultured (Figs. 2-9). In live birds, 36 from seropositive and 44 from seronegative birds were examined. From the 96 swabs, 26 isolates of bacteria were suspected as Salmonella (Table 2).

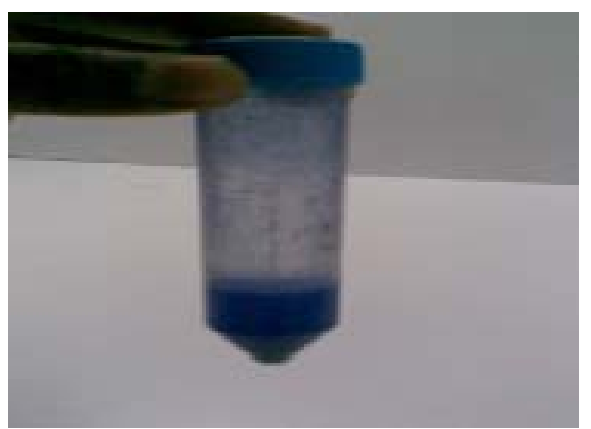

Fig. 2. Locally prepared Salmonella colored antigen

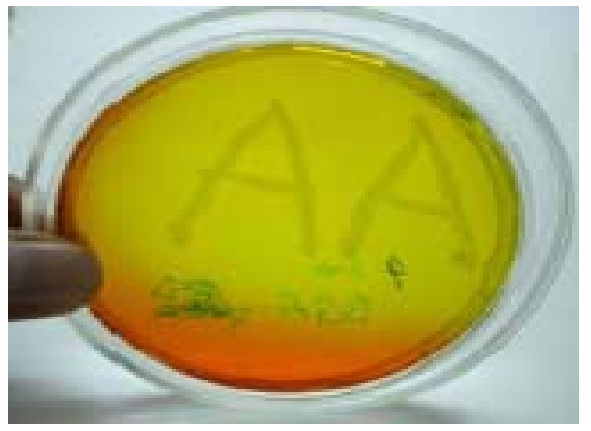

Fig. 4. Culture of Salmonella isolate No. 02 shows white colony on BGA agar

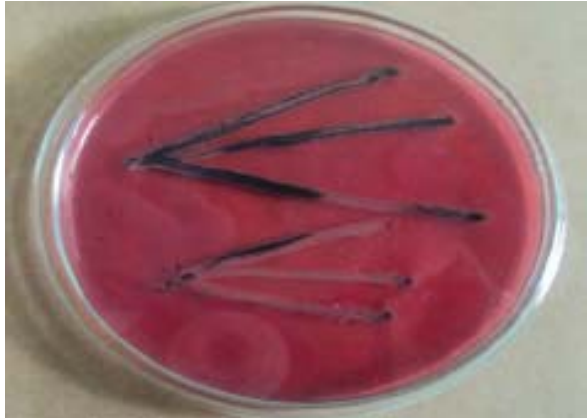

Fig. 3. Culture of Salmonella isolate No. 19 in TSI agar shows black color colonies

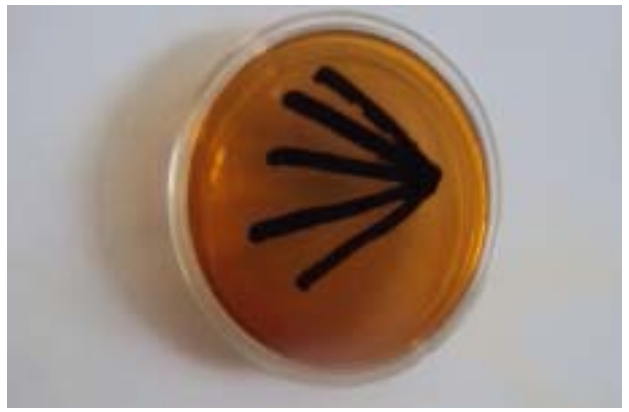

Fig. 5. Culture of Salmonella isolate No. 07 in SS agar shows whitish black color colonies 


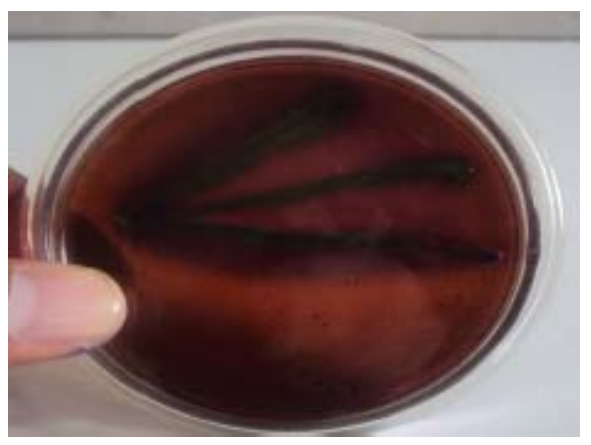

Fig. 6. Culture of Salmonella isolate No. 09 agar shows pink red colony on EMB

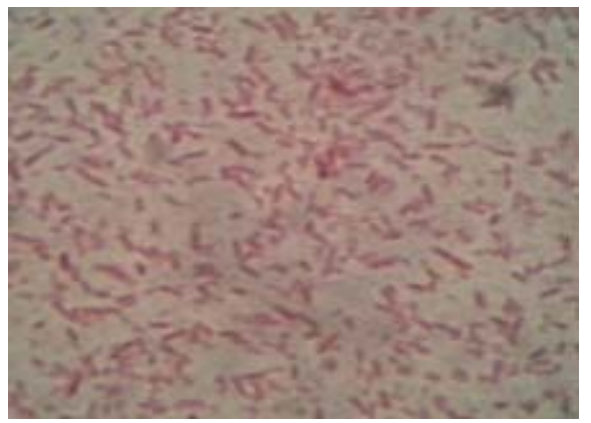

Fig. 8. Salmonella organism shows Gram negative, rod shaped, pink color bacilli in Gram's staining from isolate No. 19. $830 \mathrm{X}$

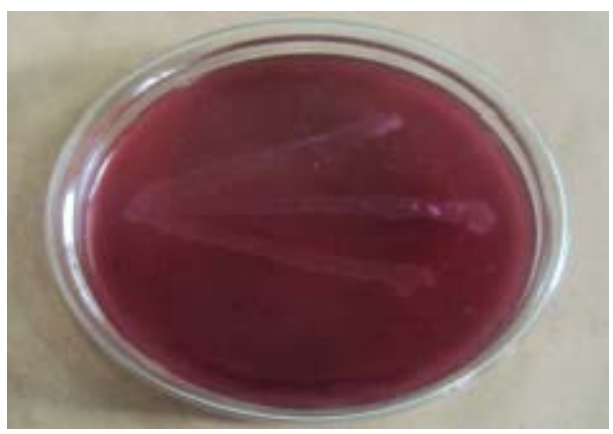

Fig. 7. Culture of Salmonella isolate No. 04 shows pale color colony on Mc. Conkey' sagar

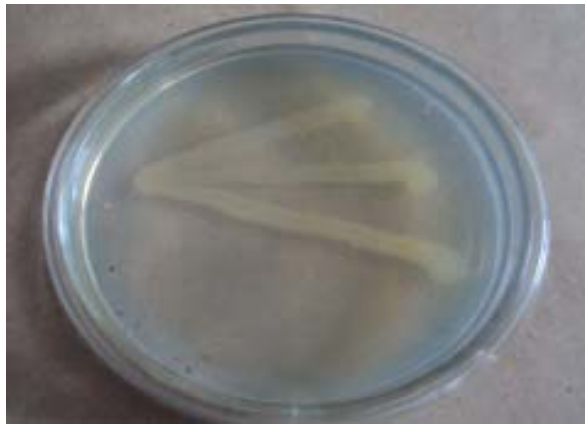

Fig. 9. Culture of Salmonella isolate No. 02 shows whitish creamy colony on nutrient agar

Table 2. Cultural prevalence of Salmonella infection of live and dead birds

\begin{tabular}{|c|c|c|c|c|}
\hline Type of birds & $\begin{array}{c}\text { No. of } \\
\text { samples }\end{array}$ & $\begin{array}{l}\text { Total No. } \\
\text { of samples }\end{array}$ & Culture in media & $\begin{array}{c}\text { Suspected } \\
\text { Salmonella isolate }\end{array}$ \\
\hline \multirow{3}{*}{ Live birds $(\mathrm{G}+\mathrm{L})$} & \multirow{3}{*}{\multicolumn{2}{|c|}{80}} & Salmonella-Shigella (SS) agar & \multirow{7}{*}{$26^{*}$} \\
\hline & & & Nutrient agar (NA) & \\
\hline & & & Brilliant green agar (BGA) & \\
\hline \multirow{4}{*}{ Dead birds $(\mathrm{G}+\mathrm{L})$} & \multirow{4}{*}{16} & \multirow[t]{4}{*}{96} & Triple sugariron (TSI) agar & \\
\hline & & & Blood agar (BA & \\
\hline & & & Mac Conkey'sagar & \\
\hline & & & Eosin methyleneblue (EMB) & \\
\hline
\end{tabular}

$(\mathrm{G}+\mathrm{L}=$ Grower + Layer $) *$ All 26 isolates showed characteristic growth pattern in 7 culture media 
Correlation between seroprevalence and cultural prevalence of Salmonella isolates

The total cultural prevalence was 33.3\% in seropositive birds (Table 3) and 22.7\% in seronegative birds (Table 4). A total of 26 Salmonella were isolated, among them $27 \%$ were Salmonella Pullorum, 58\% Salmonella Gallinarum and 15\% paratyphoid group of Salmonella (Table 5).

Table 3. Correlation between seropositive and cultural prevalence of Salmonella isolates

\begin{tabular}{l|c|c|c|c|c|c}
\hline Farm No. & $\begin{array}{c}\text { Farm } \\
\text { type }\end{array}$ & $\begin{array}{c}\text { Age of } \\
\text { birds } \\
\text { (Weeks) }\end{array}$ & $\begin{array}{c}\text { No. of tested } \\
\text { cloacal swab }\end{array}$ & $\begin{array}{c}\text { Salmonella } \\
\text { isolated in } \\
\text { culture }\end{array}$ & $\begin{array}{c}\text { Cultural } \\
\text { prevalence } \\
\%\end{array}$ & $\begin{array}{c}\text { Seropositive } \\
\text { prevalence \% }\end{array}$ \\
\hline F-1 to F-4 & Grower & $13-18$ & 18 & 7 & 38.8 & $52.6(50 / 95)^{*}$ \\
F-5 to F-8 & Layer & 22.52 & 18 & 5 & 27.7 & $38.7(31 / 80)^{*}$ \\
\hline Total & & 36 & 12 & 33.3 & $46.2(81 / 175)^{*}$ \\
\hline
\end{tabular}

$\mathrm{F}=$ Farm,${ }^{*}$ Seropositivecase/Total samples

Table 4. Correlation between seronegative and cultural prevalence of Salmonella isolates

\begin{tabular}{l|c|c|c|c|c|c}
\hline Farm No. & $\begin{array}{c}\text { Farm } \\
\text { type }\end{array}$ & $\begin{array}{c}\text { Age of } \\
\text { birds } \\
\text { (Weeks) }\end{array}$ & $\begin{array}{c}\text { No. of tested } \\
\text { cloacal swab }\end{array}$ & $\begin{array}{c}\text { Salmonella } \\
\text { isolated in } \\
\text { culture }\end{array}$ & $\begin{array}{c}\text { Cultural } \\
\text { prevalence } \\
\%\end{array}$ & $\begin{array}{c}\text { Seropositive } \\
\text { prevalence \% }\end{array}$ \\
\hline F-1 to F-4 & Grower & $13-18$ & 22 & 4 & 18 & $47.3(45 / 95)^{*}$ \\
F-5 to F-8 & Layer & 22.52 & 22 & 6 & 27 & $61.2(49 / 80)^{*}$ \\
\hline Total & & 44 & 10 & 22.7 & $53.2(94 / 175)^{*}$ \\
\hline
\end{tabular}

$\mathrm{F}=$ Farm,${ }^{*}$ Seropositivecase/Total samples

Table 5. Species identification of Salmonella from cloacal swab by biochemical test

\begin{tabular}{c|c|c|c|c}
\hline S1. No. & Species & No. of isolates & Total isolates & Prevalence (\%) \\
\hline 01 & S. Pullorum & 7 & & 27 \\
02 & S. Gallinarum & 15 & 26 & 58 \\
03 & Paratyphoid group & 4 & & 15 \\
\hline
\end{tabular}

Gross and histopathological study

On the basis of gross and histopathological lesions four birds out of 16 were diagnosed as having Salmonella infection, with the liver friable and bronze with necrotic foci (Fig. 10), severe congestion in the lung, congested haemorrhagic egg follicles with stalk formation (Fig. 11) and enlarged discoloured spleen. Microscopically, there was focal necrosis and degeneration with leukocytic infiltration in the liver (Figs. 12 and 13), congestion and pneumonic lesions in the lung and various degrees of catarrhal to haemorrhagic enteritis in the intestine. In the egg 
follicles, there was congestion and haemorrhage with leukocytic infiltration, and the spleen showed necrosis of lymphocytes.

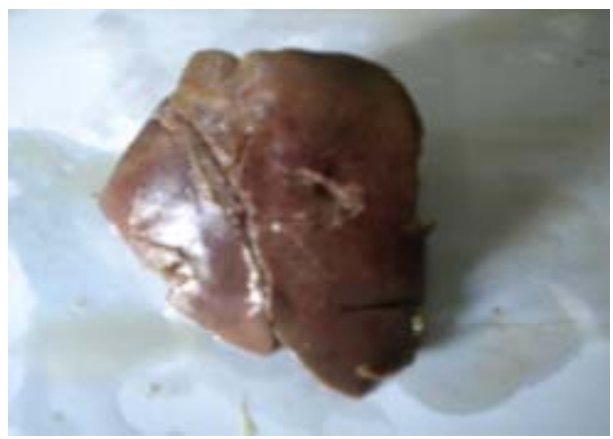

Fig. 10. Liver of Salmonella affected layer bird shows bronze discoloration and whitenecrotic foci from necropsied case No. 11

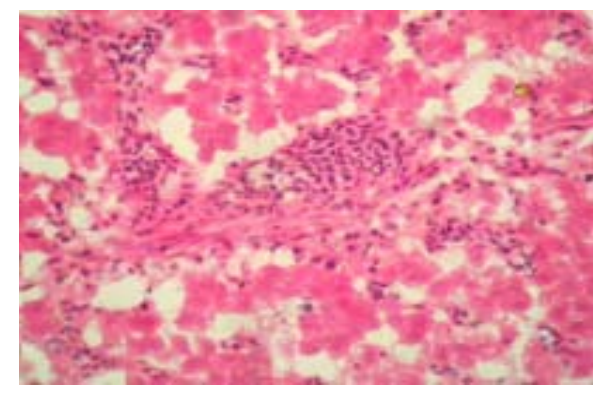

Fig. 12. Salmonella affected liver exhibits multifocal aggregation of histiocytes in liver parenchyma bird case No. 11 (H \& E staining 330X)

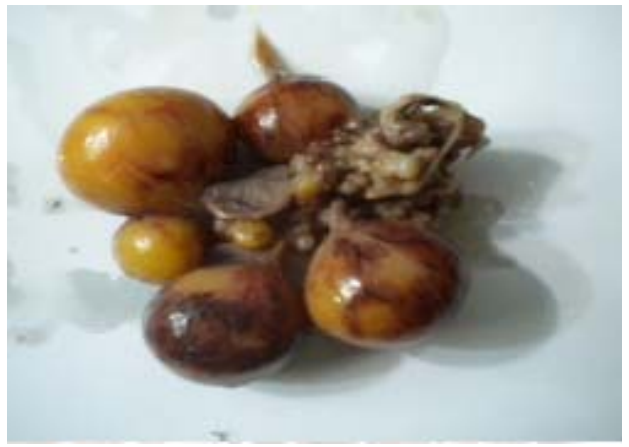

Fig. 11. Salmonella affected ovarian follicles of layer bird shows congestion, discoloration and stalk formation in case No. 1

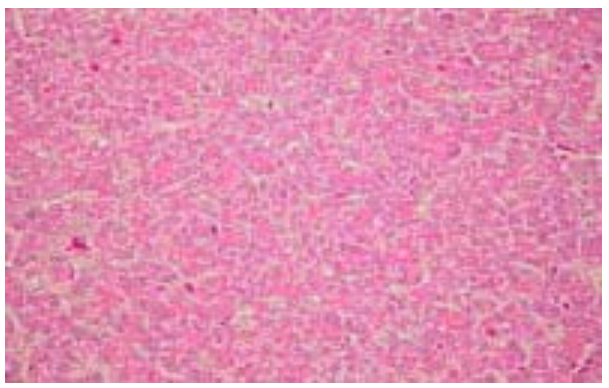

Fig. 13. Salmonella affected liver exhibits focal necrosis in hepatocytes in a bird case No. 1 (H \& E staining 83X)

During recent years poultry industry has expanded rapidly in Bangladesh and salmonellosis is a common problem causing reduced production with high mortality. The overall seroprevalence $(46.2 \%)$ is similar to that reported by Islam et al. (2006); Ahmed et al. (2008). However, Ashenafi et al. (2003); Habib-ur-Rehman et al. (2003); Jai-Sundar et al. (2007) reported $64.2 \%, 63.5 \%$ and $61.7 \%$, seroprevalence, respectively, higher than the present findings.

The seroprevalence was higher in the grower $(52.6 \%)$ and lower in the layer groups $(38.7 \%)$. In grower birds, the highest seroprevalence was at 16 weeks and lowest at 13 weeks. In contrast, Islam et al. (2007) reported increased seroprevalence with age. In this study, the variation of seroprevalence in young age might be due to vertical transmission (infection from parent stock through eggs) and horizontal transmission (infection from environment). 
The isolated Salmonella organisms were Gram-negative; rod shaped, pink and short to long chains and single or paired, similar to other investigators (Goswami et al., 2003; Haider et al., 2003).

All isolated Salmonella were MR positive and VP and indole negative. The isolated Salmonella Pullorum and Salmonella Gallinarum were dulcitol non-fermenters, but paratyphoid-causing Salmonella fermented dulcitol (Batabyal et al., 2003; Haider et al., 2003; Sujatha et al., 2003). All Salmonella isolates were lactose and sucrose negative but fermented glucose and mannitol with acid and gas production. Salmonella Pullorum did not ferment maltose, while others fermented maltose (Batabyal et al., 2003; Haider et al., 2003; Sujatha et al., 2003).

Twenty-two isolates (Salmonella Pullorum and Salmonella Gallinarum) were nonmotile and four isolates (paratyphoid-causing Salmonella) were motile (Christensen et al., 1996; Islam et al., 2007). Among the 26 isolates, 27\% ( $\mathrm{n}=7)$ were identified as Salmonella Pullorum, 58\% (15) Salmonella Gallinarum and $15 \%(\mathrm{n}=4)$ were paratyphoid-causing Salmonella. The overall seroprevalence of Salmonella was $46.2 \%$ (52.6\% in growers; $38.7 \%$ in layers). Higher isolation rate in seropositive birds (46.2\%) may be due to repeated exposure of Salmonella infection. Truong and Tieuquang (2003) obtained 66\% Salmonella seropositive but they did not explain the mechanism of obtaining this higher rate. In seronegative birds the isolation rate was $53.2 \%$. It might be assumed that after Salmonella infection, time did not elapse for antibody production. The cultural prevalence of Salmonella in seropositive birds was 33.3\% (38.8\% in growers; $27.7 \%$ in layers) and in seronegative birds the cultural prevalence was $22.7 \%$ (18\% in growers; $7 \%$ in layers) but in dead birds the prevalence was $25 \%$ from the cloacal and liver sample. Habib-ur-Rehman et al. (2003) described 34.5\% cultural prevalence of Salmonella infection in liver while Lee et al. (2003) described $47.6 \%$. In the present study, the prevalence of Salmonella in dead birds is supported by other investigators (Lee et al., 2003).

Similar pathological findings were described by many investigators (Syed-Habibur-Rehman et al., 2004; Msoffe et al., 2006; Islam et al., 2007; Deshmukh et al., 2007). The microscopic lesions in present study were similar to those described by other authors (Msoffe et al., 2006; Deshmukh et al., 2007; Ahmed et al., 2008).

\section{Conclusions}

The presence of antibody was not directly related with the presence of organisms in the digestive tract. Seroprevalence, culture and pathological examination should be performed simultaneously for confirmation of Salmonella infections in a poultry farm. Further studies with serotyping, vaccine production and antibiotic sensitivity determination with isolated Salmonella from poultry may be performed in the near future. 


\section{References}

Ahmed AKM, Islam MT, Haider MG, Hossain MM 2008: Seroprevalence and pathology of naturally infected salmonellosis in poultry with isolation and identification of causal agents. Journal of Bangladesh Agricultural University 6 327-334.

Amick-Morris J 1998: Insects' contribution to Salmonella transmission in turkey flocks. MS Thesis West Virginia University, Morgantown, WV, USA.

Ashenafi H, Shetu Y, Oldemeskel M 2003: Identification of major infections of local chickens of Central Ethiopia. Bulletin Animal Health and Production, Africa 51 95-101.

Batabyal K, Das R, Ghosh RN 2003: Characterization of Salmonella Gallinarum isolated from quail sources along with its antibiogram. Indian Veterinary Journal 80 209-211.

Berchieri Jr A, Murphy CK, Marston K, Barrow PA 2001: Observations on the persistence and vertical transmission of Salmonella enterica serovars Pullorum and Gallinarum in chickens effect of bacterial and host genetic background. Avian Pathology 30 221-231.

Bouzoubaa K, Lemainguer K, Bell JG 1992: Village chickens as a reservoir of Salmonella Pullorum and Salmonella gallinarum in Morocco. Preventive Veterinary Medicine 12 95-100.

Christensen JP, Brown DJ, Madsen M, Olsen JE, Bisgaard M 1997 Hatchery borne Salmonella enterica serover Tennessee infections in broilers. Avian Pathology 26 155-167.

Deshmukh S, Asrani RK, Ledoux DR, Rottinghaus GE, Bermudez AJ, Gupta VK 2007: Pathologic changes in extrahepatic organs and agglutinin response to Salmonella Gallinarum infection in Japanese quail fed Fusarium verticillioides culture material containing known levels of fumonisin B1. Avian Diseases 51 705-712.

Goswami P, Chakraborti A, Hui AK, Das R, Sarkar P, Som TL 2003: Isolation and identification of Salmonella Gallinarum form field cases and their antibiogram. Indian Veterinary Microbiology Journal 80 184-185.

Habib-ur-Rehman, Sirzanin S, Hamayun K, Saleem K, Nazir A, Bhatti WM 2003: Incidence and gross pathology of salmonellosis in chicken in Hyderabad. Journal of Association of Veterinary Advances 2 581-584.

Haider MG, Hossain MG, Hossain MS, Chowdhury EH, Das PM, Hossain MM 2003: Isolation and characterization of enterobacteria associated with health and disease in Sonali chickens. Bangladesh Journal of Veterinary Medicine 2 15-21.

Haider, MG, Chowdhury, EH, Khan, MAHNA, Hossain, MT, Rahman, MS, Song, HJ and Hossain, MM 2008. Experimental Pathogenesis of Pullorum Disease with the Local Isolate of Salmonella enterica serovar. enterica subspecies Pullorum in Pullets in Bangladesh. Korean Journal of Poultry Science 35 341-350.

Hoover NJ, Kenney PB, Amick JD, Hypes WA 1997: Preharvest sources of Salmonella colonization in turkey production. Poultry Science 76 1232-1238.

Islam MM, Hossain MM, Haider MG, Chowdhury EH, Kamruzzaman M 2007: Seroprevalence and pathological study of Salmonella infections in layer chickens and isolation of causal agents: In Proceedings of the $5^{\text {th }}$ International Poultry show and seminar, 0103 March, China Friendship Conference Centre (CFCC), Sher-e-Bangla Nagar, Dhaka, Bangladesh pp. 9-15. 
Jai-Sundar, Rai RB, Kundu A, Senani S, Chatterjee RN, Jeyakumar S 2007: Seroprevalence of poultry diseases in Andaman and Nicobar Islands. Indian Veterinary Journal 84 95-96.

Jones FT, Axtell RC, Rives DV, Scheideler SE, Tarver J, Walker RL, Wineland MJ 1991: A survey of Salmonella contamination in modern broiler production. Journal of Food Protection 54 502-507.

Khan AHMNA, Bari ASM, Islam MR, Das PM, Ali MY 1998: Pullorum disease in semi mature chickens and its experimental pathology. Bangladesh Veterinary Journal 32 124-128.

Lee YJ, Kim KS, Kwon YK, Kang MS, Mo IP, Kim JH, Tak RB 2003: Prevalent characteristics of fowl typhoid in Korea. Journal of Veterinary Clinics 20 155-158.

Luna LG 1968. Manual and Histologic Staining Methods of the Armed Forces Institute of Pathology. $3^{\text {rd }}$ Edn. McGraw Hill Book Co, New York, USA pp. 85-86.

Merchant IA, Packer RA 1967: Veterinary Bacteriology and Virology. $7^{\text {th }}$ edn, The Iowa State University Press, Ames, Iowa, USA pp. 211- 306.

Msoffe PLM, Minga UM, Mtambo MMA, Gwakisa PS, Olsen JE 2006: Differences in resistance to Salmonella enterica serovar Gallinarum infection among indigenous local chicken ecotypes in Tanzania. Avian Pathology 35 270-276.

Muktaruzzaman M, Haider MG, Ahmed A KM, Alam KJ, Rahman MM, Khatun MB, Rahman MH, Hossain MM 2010: Validation and Refinement of (SP) Colored Antigen for Diagnosis of Salmonella Infections in the Field. International Journal of Poultry Science 9 801-808.

(OIE) Office International Des Epizooties 2004: OIE Manual Part-2: Pullorum Diseases and Fowl Typhoid In: OIE Manual Diagnostic Tests and Vaccines for Terrestrial Animals. $4^{\text {th }}$ edn. Paris, France.

Sujatha K, Dhanalakshmi K, Rao AS 2003: Isolation and characterization of S. Gallinarum from chicken. Indian Veterinary Journal 80 473-474.

Syed-Habib-ur-Rehman, Khan MS, Hamayun K, Nazir A, Bhatii WM 2004: Incidence and gross pathology of Salmonella Gallinarum infection in chicken. Journal of Animal and Veterinary Advances 3 175-178.

Truong Q, Tieuquang AN 2003: Prevalence of Salmonella Gallinarum Pullorum infection in the Luong Phuong chickens reared in the household sector. Veterinary Science and Technique 10 15-19.

Wigley P, Berchieri A Jr, Page KL, Smith AL, Barrow PA 2001: Salmonella enterica serovar Pullorum persists in splenic macrophages and in the reproductive tract during persistent, disease free carriage in chickens. Infection and Immunology 69 591-592.

World Poultry VIV 2008: WWW. World Poultry. Net/Poultry. Salmonella Pullorum. 